\title{
Angiotensin II type 1 receptors and systemic hemodynamic and renal responses to stress and altered blood volume in conscious rabbits
}

\author{
Tony B. X $u^{1}$, Gabriela A. Eppel' , Geoffrey A. Head ${ }^{2}$ and Roger G. Evans ${ }^{1}{ }^{*}$ \\ 1 Department of Physiology, Monash University, Melbourne, VIC, Australia \\ ${ }^{2}$ Baker IDI Heart and Diabetes Institute, Melbourne, VIC, Australia
}

Edited by:

Ged Davis, University of Otago,

New Zealand

Reviewed by:

Mildred Audrey Pointer, North

Carolina Central University, USA

Irving H. Zucker, University of

Nebraska Medical Center, USA

*Correspondence:

Roger G. Evans, Department of Physiology, Monash University,

PO Box 13F, Melbourne, VIC 3800 , Australia.

e-mail: roger.evans@med.monash. edu.au
We examined how systemic blockade of type 1 angiotensin $\left(\mathrm{AT}_{1^{-}}\right)$receptors affects reflex control of the circulation and the kidney. In conscious rabbits, the effects of candesartan on responses of systemic and renal hemodynamics and renal excretory function to acute hypoxia, mild hemorrhage, and plasma volume expansion were tested. Candesartan reduced resting mean arterial pressure (MAP, $-8 \pm 2 \%$ ) without significantly altering cardiac output $(\mathrm{CO})$, increased renal blood flow $(\mathrm{RBF},+38 \pm 9 \%)$ and reduced renal vascular resistance (RVR, $-32 \pm 6 \%$ ). Glomerular filtration rate (GFR) was not significantly altered but sodium excretion $\left(U_{N a+} V\right)$ increased fourfold. After vehicle treatment, hypoxia (10\% inspired $\mathrm{O}_{2}$ for $30 \mathrm{~min}$ ) did not significantly alter MAP or $\mathrm{CO}$, but reduced heart rate $(H R,-17 \pm 6 \%)$, increased $R V R(+33 \pm 16 \%)$ and reduced GFR $(-46 \pm 16 \%)$ and $\mathrm{U}_{\mathrm{Na}+} \mathrm{V}(-41 \pm 17 \%)$. Candesartan did not significantly alter these responses. After vehicle treatment, plasma volume expansion increased $\mathrm{CO}(+35 \pm 7 \%)$, reduced total peripheral resistance (TPR, $-26 \pm 5 \%)$, increased RBF $(+62 \pm 23 \%)$ and reduced RVR $(-32 \pm 9 \%)$, but did not significantly alter MAP or HR. It also increased $U_{\mathrm{Na}+} \mathrm{V}(803 \pm 184 \%)$ yet reduced GFR $(-47 \pm 9 \%)$. Candesartan did not significantly alter these responses. After vehicle treatment, mild hemorrhage did not significantly alter MAP but increased HR $(+16 \pm 3 \%)$, reduced $\mathrm{CO}(-16 \pm 4 \%)$ and $\operatorname{RBF}(-18 \pm 6 \%)$, increased TPR $(+18 \pm 4 \%)$ and tended to increase RVR $(+18 \pm 9 \%, P=0.1)$, but had little effect on GFR or $U_{N a+} V$. But after candesartan treatment MAP fell during hemorrhage $(-19 \pm 1 \%)$, while neither TPR nor RVR increased, and GFR $(-64 \pm 18 \%)$ and $U_{N a+} \mathrm{V}(-83 \pm 10 \%)$ fell. $A T_{1}$-receptor activation supports MAP and GFR during hypovolemia. But $A T_{1}$-receptors appear to play little role in the renal vasoconstriction, hypofiltration, and antinatriuresis accompanying hypoxia, or the systemic and renal vasodilatation and natriuresis accompanying plasma volume expansion.

Keywords: angiotensin II, cardiovascular reflex, hemorrhage, hypoxia, plasma volume expansion

\section{INTRODUCTION}

Drugs that interfere with the function of the renin-angiotensin system (RAS) are the most commonly prescribed class of agents for the treatment of hypertension (Muntner et al., 2009; Vitry and Lai, 2009). These include inhibitors of angiotensin converting enzyme, angiotensin II type $1\left(\mathrm{AT}_{1}\right)$ receptor antagonists, and the more recently introduced direct renin inhibitors (Riccioni et al., 2010). One of the hallmarks of these agents is the relative lack of adverse effects such as postural hypotension (Hajjar, 2005) and salt and water retention (Sharma, 2004), which are seen with some other antihypertensive agents.

It is generally accepted that antihypertensive agents that target the RAS system do not impede reflex control of the circulation to the same extent as many other therapeutic modalities (Fridman et al., 1999). This property, in turn, is believed to contribute to their tolerability (Hajjar, 2005). On the other hand, an ability to impede pro-hypertensive circulatory and renal responses to stimuli such as hypoxia and hypovolemia, or to enhance antihypertensive compensatory responses to hypervolemia, could potentially contribute to their antihypertensive efficacy. Yet there is a general lack of consensus regarding the effects of $\mathrm{AT}_{1}$-receptor antagonists on reflex control of the circulation and the kidney.

The effects of angiotensin receptor antagonists on the blood pressure response to hemorrhage have been studied extensively in multiple species. For example, blockade of angiotensin II receptors reduced mean arterial pressure (MAP) after hemorrhage in conscious dogs (Spielman et al., 1975). It also blunted the recovery of MAP after hemorrhage in conscious rats, without altering the acute response of MAP to blood loss (Ponchon and Elghozi, 1997). Other studies have demonstrated an augmented depressor response to hemorrhage after blockade of central $\mathrm{AT}_{1}$-receptors in conscious rats (Lee et al., 1995) or systemic $\mathrm{AT}_{1}$-receptor blockade in conscious dogs (Francis et al., 2004), or an early occurrence of the decompensatory phase of the response to progressive hypovolemia in conscious sheep after central $\mathrm{AT}_{1}$-receptor blockade (Mathai et al., 1997). Yet in only one of these studies was cardiac 
output (CO) measured (Francis et al., 2004) and in none was renal blood flow (RBF) measured. The one study are aware of, in which the effects of RAS inhibition on responses of RBF to hemorrhage were assessed, examined the effects of combined blockade of angiotensin converting enzyme and vasopressin $\mathrm{V}_{1}$-receptors (Courneya and Korner, 1991). Thus, the specific roles of $\mathrm{AT}_{1^{-}}$ receptors in responses of renal and systemic vascular resistance to hemorrhage remain largely unexplored. The effects of systemic angiotensin receptor blockade on hemodynamic and renal responses to other cardiovascular reflexes, such as those evoked by hypoxemia, have been studied in anesthetized animals (Neylon et al., 1996). But because such responses are likely affected by anesthesia, studies in conscious animals are warranted.

In the current study we tested the hypothesis that $\mathrm{AT}_{1}$-receptor blockade affects responses of the circulation and kidney to circulatory stressors in a manner that would be expected to contribute toward the antihypertensive efficacy of this therapeutic modality. Therefore, we aimed to examine the impact of candesartan on hemodynamic and renal responses to hemorrhage, hypoxia, and plasma volume expansion, in chronically instrumented conscious rabbits.

\section{MATERIALS AND METHODS ANIMALS}

Male New Zealand White rabbits $(n=7,3.22 \pm 0.13 \mathrm{~kg}$ at the time of their first experimental observations) were studied, according to the Australian Code of Practice for the Care and Use of Animals for Scientific Purposes. The experimental protocol was approved in advance by the Animal Ethics Committee of the School of Biomedical Sciences, Monash University. After recovery from preliminary surgery, each rabbit was studied on four separate experimental days at 1 week intervals. During these experiments we examined responses to hypoxia and plasma volume expansion (after administration of candesartan or its vehicle) or hemorrhage (after candesartan or its vehicle). The order of the treatments was randomized.

\section{PRELIMINARY SURGERY \\ Major procedures}

Each rabbit underwent two surgical procedures. For both, anesthesia was induced with i.v. propofol (10 mg/kg; Diprivan, ICI, VIC, Australia), and following endotracheal intubation, maintained with isoflurane (1-4\% w/v; Isoflo, Abbott Australasia, Kurnell, NSW, Australia). The first procedure involved implantation of a transit-time ultrasound flow probe (type 6SB, Transonic Systems, Ithaca, USA) around the ascending aorta via a left thoracotomy, for later measurement of CO (Shweta et al., 1999). At the second operation, performed 2 weeks after the first, a transit-time flow probe (type 2SB, Transonic Systems, Ithaca, USA) was implanted around the left renal artery for measurement of RBF (Shweta et al., 1999). The connectors of the flow probes were tunneled subcutaneously for later retrieval on the day of the experiment. Experimental studies commenced at least 2 weeks after the second surgical procedure.

\section{Minor procedures on study days}

These were performed under local analgesia ( $1 \% \mathrm{w} / \mathrm{v}$ lignocaine, Xylocaine, AstraZeneca, NSW, Australia). Catheters (Optiva,
Johnson \& Johnson, NSW, Australia) were placed in the marginal ear vein for infusion of drugs, and central ear artery for measurement of arterial pressure. The flow probe connectors were retrieved from their subcutaneous positions. The rabbit was then briefly anesthetized (propofol, $10 \mathrm{mg} / \mathrm{kg}$, i.v.) to allow insertion of a bladder catheter (Rusch Symcath, $2.7 \mathrm{~mm}$ pediatric, Teleflex Medical, Kamunting, Malaysia). All rabbits regained consciousness, as assessed by the righting reflex, within 5 min of placement of the catheter. $\left[{ }^{3} \mathrm{H}\right]$-inulin (Perkin Elmer, Rowville, Australia) was then administered as a bolus of $10 \mu \mathrm{Ci}$ in $0.5 \mathrm{ml}$ and an infusion of $34.4 \mathrm{nCi} / \mathrm{kg} / \mathrm{min}$. The $\left[{ }^{3} \mathrm{H}\right]$-inulin infusion, which continued for the day's experimental protocol (see below), was administered in an isotonic solution of glucose $(4 \% \mathrm{w} / \mathrm{v})$ and $\mathrm{NaCl}(0.18 \%$ $\mathrm{w} / \mathrm{v}$ ) delivered intravenously at a rate of $0.1 \mathrm{ml} / \mathrm{kg} / \mathrm{min}$. This fluid regimen, which is similar to that which we have used previously (Tomoda et al., 1996; Norman et al., 2001), induces some degree of diuresis but not natriuresis. An equilibration period of $60 \mathrm{~min}$ was allowed, from administration of the $\left[{ }^{3} \mathrm{H}\right]$-inulin bolus, before the experimental protocol began.

\section{EXPERIMENTAL PROTOCOLS}

Each experiment consisted of a series of 20 min clearance periods, during which urine was collected. At the mid-point of each clearance period, a $0.5-\mathrm{ml}$ sample of arterial blood was collected to facilitate renal clearance measurements. After an initial control clearance period, either candesartan $(10 \mu \mathrm{g} / \mathrm{kg}+10 \mu \mathrm{g} / \mathrm{kg} / \mathrm{h})$ or its vehicle $(1 \mathrm{ml} / \mathrm{kg}+1 \mathrm{ml} / \mathrm{kg} / \mathrm{h}$ of $0.9 \% \mathrm{w} / \mathrm{v} \mathrm{NaCl})$ was administered. A second 20 min clearance period then commenced $30 \mathrm{~min}$ after treatment with candesartan or its vehicle began.

On each experimental day, we then tested responses to either hypoxia and plasma volume expansion, or hemorrhage. The hypoxia protocol comprised three $30 \mathrm{~min}$ periods, during which the rabbit breathed room air, a mixture of $10 \%$ oxygen with $4 \%$ carbon dioxide, and then room air again. Carbon dioxide was added to the inspired gas mixture to prevent development of hypocapnia during hypoxia (Blake et al., 1994). Gas mixtures were delivered at a rate of $21 / \mathrm{min}$ into a specially designed rabbit holding box constructed from plastic material so as to be air-tight. Renal clearance measurements were obtained over the final $20 \mathrm{~min}$ of each of the three $30 \mathrm{~min}$ experimental periods. An additional $0.5 \mathrm{ml}$ sample of arterial blood was collected at the midpoint of each of these clearance periods, for blood gas analysis. After a further $30 \mathrm{~min}$ recovery period, responses to plasma volume expansion were then examined over a series of five clearance periods. After a control period, a polygeline/electrolyte solution (Gelofusine, B. Braun Pty Ltd., Bella Vista, NSW, Australia) was administered intravenously at a rate of $1 \mathrm{ml} / \mathrm{kg} / \mathrm{min}$ for $30 \mathrm{~min}$. Upon completion of the infusion, a series of four consecutive 20 min clearance periods commenced. On separate study days, responses to hemorrhage were examined after administration of candesartan or its vehicle. Responses to progressive hemorrhage and re-infusion of shed blood were examined over a series of four experimental periods. After a control period, $6 \mathrm{ml} / \mathrm{kg}$ blood was removed via the ear artery, over a 5 -min period. Five minutes later, a second clearance period commenced. A further $6 \mathrm{ml} / \mathrm{kg}$ blood was then removed over a 5 -min period, and 5 min later a third clearance period commenced. The shed blood was then returned 
to the rabbit intravenously over a 10 -min period. Ten minute after completing blood infusion, a fourth clearance period commenced.

At the end of each study day we tested responses to an intravenous bolus of angiotensin II $(100 \mathrm{ng} / \mathrm{kg})$. The effectiveness of candesartan was confirmed by the absence of a pressor response to angiotensin II after candesartan treatment. After vehicle treatment, angiotensin II increased MAP by approximately $27 \pm 4 \mathrm{mmHg}$, but only by $3 \pm 2 \mathrm{mmHg}$ after candesartan treatment.

\section{MEASUREMENTS}

Arterial pressure was measured via an ear artery catheter connected to a pressure transducer (Cobe, Arvada, CO, USA) and bridge amplifier (Model QA1; Scientific Concepts, Mount Waverley, VIC, Australia). The transit-time ultrasound flow probes were connected to a compatible flowmeter (Model T206; Transonic Systems Inc.). Values of MAP, heart rate (HR, triggered by the arterial pressure pulse), CO, and RBF were digitized as $2 \mathrm{~s}$ averages (Guild et al., 2002). Total peripheral resistance (TPR) was calculated as the quotient of MAP and CO, while renal vascular resistance (RVR) was calculated as the quotient of MAP and RBF. Vena caval pressure increases by only $3 \mathrm{mmHg}$ during plasma volume expansion (Shweta et al., 1999) and likely falls by only $\sim 2 \mathrm{mmHg}$ during mild hemorrhage (Ludbrook and Graham, 1984). Thus, errors due to the absence of venous pressure in our calculations of TPR and RVR are likely small. Blood gas analysis was performed on $0.5 \mathrm{ml}$ blood samples using an ABL 700 series blood gas analyzer (Radiometer Copenhagen). Glomerular filtration rate (GFR) was measured as the clearance of $\left[{ }^{3} \mathrm{H}\right]$-inulin. Sodium concentrations in plasma and urine were determined using a Synchron CX5 Clinical System (Beckman-Coulter).

\section{STATISTICS}

Values were averaged over each clearance period and are expressed as mean \pm SEM. Hypothesis testing was performed using the software package SYSTAT (Version 10; SPSS, Chicago, IL, USA). Two sided $P \leq 0.05$ was considered statistically significant. Paired $t$ tests were used to test for acute responses to candesartan or its vehicle, examined over the first two clearance periods of each study day, or for other comparisons between successive experimental periods. Because responses to candesartan and its vehicle were determined twice in each rabbit, analysis of these data was performed using the within-rabbit mean values for each variable. Responses to hypoxia, plasma volume expansion, and hemorrhage were then examined using two-way repeated measures analysis of variance (Ludbrook, 1994). The main effect of the categorical variable "time" tested whether, independent of pre-treatment (candesartan or its vehicle), the various experimental maneuvers altered the level of each variable. The main effect of the categorical variable "treatment" tested whether, independent of time, the levels of each variable differed after treatment with candesartan compared with its vehicle. The "treatment X time" interaction term tested whether candesartan treatment altered responses to each maneuver.

\section{RESULTS}

All seven rabbits completed the entire experimental protocol. However, in three rabbits the renal artery flow probe was dysfunctional. Consequently, $n=7$ for all observations except for RBF, for which $n=4$.

\section{ACUTE EFFECTS OF CANDESARTAN}

Administration of candesartan induced a fall in MAP $(-8 \pm 2 \mathrm{mmHg})$ and increased $\mathrm{HR}(+14 \pm 5$ beats/min $)$ and $\mathrm{RBF}$ $(+38 \pm 9 \%)$, but no significant change in CO was observed. RVR fell by $-32 \pm 6 \%$. GFR was not significantly altered by candesartan treatment, but sodium excretion and the fractional excretion of sodium both increased more than fourfold. The vehicle for candesartan did not significantly affect any of the measured hemodynamic or renal variables (Table 1).

\section{RESPONSES TO HYPOXIA}

After vehicle treatment, exposure to the hypoxic gas mixture reduced arterial $\mathrm{PO}_{2}$ (by $-66 \pm 8 \mathrm{mmHg}$ ) and hemoglobin saturation (from $100 \pm<1$ to $64 \pm 5 \%$ ) and increased $\mathrm{PCO}_{2}$ (by

Table 1 | Responses of hemodynamic, and renal function variables to candesartan, and its vehicle.

\begin{tabular}{|c|c|c|c|c|c|c|}
\hline \multirow[t]{2}{*}{ Variable } & \multicolumn{3}{|c|}{ Vehicle } & \multicolumn{3}{|c|}{ Candesartan } \\
\hline & Before & After & $\boldsymbol{P}$ & Before & After & $\boldsymbol{P}$ \\
\hline $\mathrm{MAP}(\mathrm{mmHg})$ & $97 \pm 1$ & $97 \pm 1$ & 0.95 & $95 \pm 3$ & $87 \pm 2$ & 0.01 \\
\hline HR (beats/min) & $241 \pm 10$ & $241 \pm 9$ & 0.93 & $246 \pm 8$ & $260 \pm 10$ & 0.02 \\
\hline $\mathrm{CO}(\mathrm{ml} / \mathrm{min})$ & $444 \pm 31$ & $450 \pm 30$ & 0.59 & $456 \pm 35$ & $459 \pm 48$ & 0.88 \\
\hline $\mathrm{TPR}(\mathrm{mmHg} / \mathrm{ml} \mathrm{min})$ & $0.23 \pm 0.02$ & $0.23 \pm 0.02$ & 0.59 & $0.22 \pm 0.02$ & $0.20 \pm 0.02$ & 0.16 \\
\hline $\operatorname{RBF}(\mathrm{ml} / \mathrm{min})$ & $44.1 \pm 3.9$ & $40.9 \pm 5.5$ & 0.31 & $44.0 \pm 4.7$ & $61.3 \pm 8.5$ & 0.04 \\
\hline $\mathrm{RVR}(\mathrm{mmHg} / \mathrm{ml} \mathrm{min})$ & $2.30 \pm 0.18$ & $2.54 \pm 0.31$ & 0.35 & $2.16 \pm 0.17$ & $1.49 \pm 0.20$ & 0.01 \\
\hline GFR (ml/min) & $18.0 \pm 3.2$ & $17.9 \pm 4.4$ & 0.98 & $16.6 \pm 3.8$ & $16.6 \pm 1.9$ & 0.99 \\
\hline $\mathrm{U}_{\mathrm{Na}+} \mathrm{V}(\mu \mathrm{mol} / \mathrm{min})$ & $19.6 \pm 6.6$ & $13.8 \pm 3.1$ & 0.42 & $24.1 \pm 9.9$ & $101.0 \pm 32.9$ & 0.03 \\
\hline $\mathrm{FE}_{\mathrm{Na}+}(\%)$ & $0.7 \pm 0.2$ & $0.7 \pm 0.2$ & 0.84 & $0.9 \pm 0.3$ & $4.2 \pm 1.3$ & 0.02 \\
\hline
\end{tabular}

Values represent mean $\pm S E M$ of seven observations, except for RBF and RVR, for which $n=4$ because the renal artery flow probe was not operational in three rabbits. MAP, mean arterial pressure; $H R$, heart rate; $C O$, cardiac output; $R B F$, renal blood flow; $R V R$, renal vascular resistance; GFR, glomerular filtration rate; $U_{\text {Na+ }} V$, sodium excretion; $F E_{\mathrm{Na}+}$, the fractional excretion of sodium. $P$ values were generated from paired $t$-tests. 
$10 \pm 3 \mathrm{mmHg}$ ) and tended to reduce arterial $\mathrm{pH}$ (by $-0.10 \pm 0.05$ units). During the recovery period after exposure to the hypoxic gas mixture, these variables returned to their control level. Responses of blood gas variables to the hypoxic gas mixture after candesartan treatment were indistinguishable from those after vehicle treatment (Figure 1).

After vehicle treatment, hypoxia did not significantly alter MAP, CO, or TPR, but reduced HR (by $-44 \pm 16$ beats $/ \mathrm{min}$ ) and tended to reduce $\mathrm{RBF}$ (by $-21 \pm 8 \%, P=0.08$ ) and increase RVR (by $33 \pm 16 \%$ ). Although candesartan treatment altered baseline levels of MAP, RBF, and RVR, it did not significantly alter the hemodynamic responses to hypoxia (Figure 2).

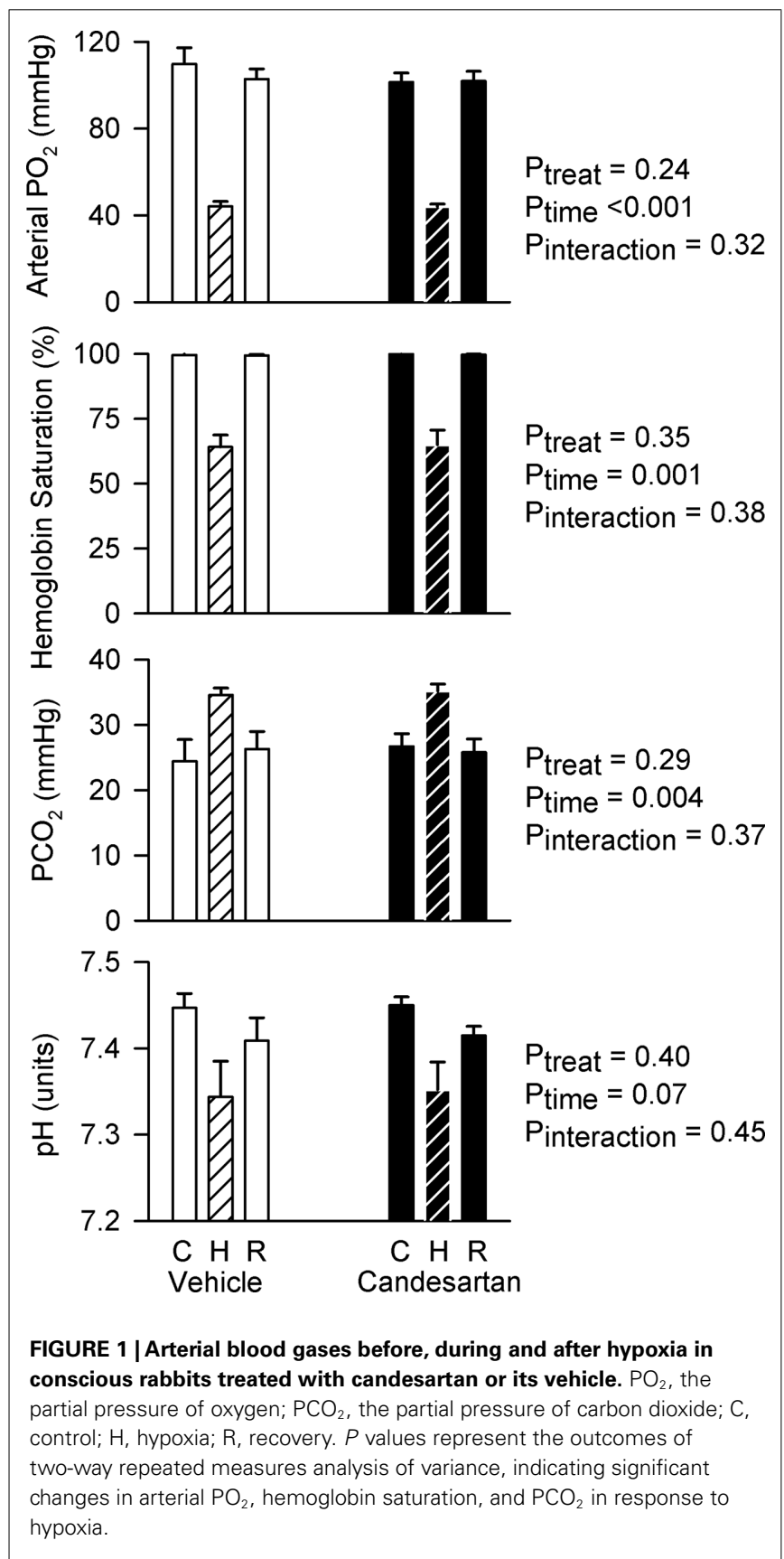

After vehicle treatment, hypoxia tended to reduce GFR (by $-46 \pm 16 \%, P=0.06$ ) and sodium excretion (by $-41 \pm 17 \%$, $P=0.06)$. Similar reductions in GFR and sodium excretion were observed during hypoxia after candesartan treatment. Thus, although candesartan altered the baseline levels of these variables, it had little impact on their responses to hypoxia (Figure 3).

\section{RESPONSES TO PLASMA VOLUME EXPANSION}

After vehicle treatment, infusion of the polygeline/electrolyte solution reduced hematocrit from $40.0 \pm 0.6$ to $28.7 \pm 0.7 \%$, corresponding to a nominal plasma volume expansion of $66 \pm 3 \%$ and total blood volume expansion of $40 \pm 2 \%$. Hematocrit rose slightly across the subsequent $80 \mathrm{~min}$, but always remained below its control level. Hematocrit was slightly greater after treatment with candesartan than vehicle $(3.2 \pm 1.2 \%$ when averaged over all five clearance periods). However, the response to the infusion was indistinguishable after candesartan treatment compared with after vehicle treatment (Figure 4).

Plasma volume expansion was accompanied by increased $\mathrm{CO}$ $(+35 \pm 7 \%$ during the first clearance period after infusion of polygeline/electrolyte solution) and reduced TPR $(-26 \pm 5 \%)$, increased RBF $(+62 \pm 23 \%)$ and reduced RVR $(-32 \pm 9 \%)$, but little change in MAP or HR (Figure 5). There were also increases in sodium excretion $(803 \pm 184 \%)$ and the fractional excretion of sodium (from $1.04 \pm 0.37$ to $17.83 \pm 6.74 \%$ ), and a decrease
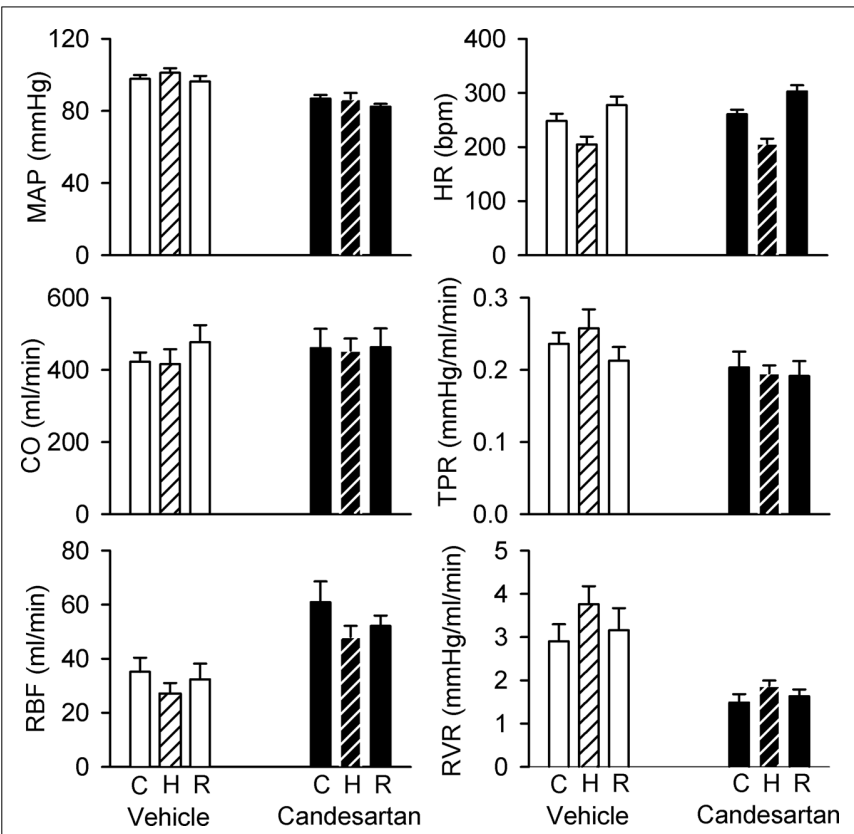

FIGURE 2 | Responses of hemodynamic variables to hypoxia in conscious rabbits treated with candesartan or its vehicle. MAP, mean arterial pressure; $\mathrm{HR}$, heart rate; $\mathrm{CO}$, cardiac output; $\mathrm{RBF}$, renal blood flow; TPR, total peripheral resistance; RVR, renal vascular resistance; $C$, control; $\mathrm{H}$, hypoxia; $\mathrm{R}$, recovery. $P$ values for the outcomes of two-way repeated measures analysis of variance are shown in Table 2. These indicate significant effects of candesartan on MAP, RBF, TPR, and RVR, and a significant effect of hypoxia on HR. However, candesartan did not significantly affect responses to hypoxia. 

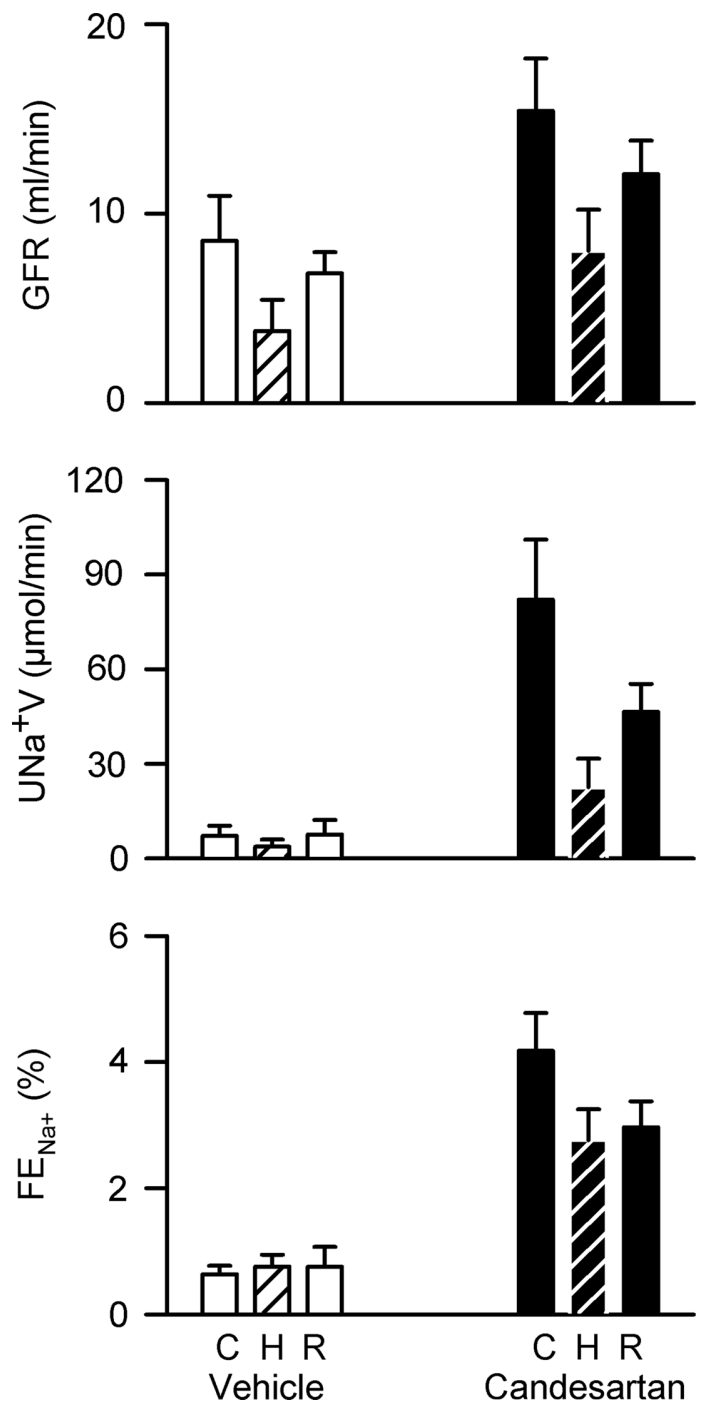

FIGURE 3 | Responses of renal excretory variables to hypoxia in conscious rabbits treated with candesartan or its vehicle. GFR, glomerular filtration rate, $U_{\mathrm{Na}+} \mathrm{V}$, sodium excretion; $\mathrm{FE}_{\mathrm{Na}+}$, fractional sodium excretion; $\mathrm{C}$, control; $\mathrm{H}$, hypoxia; $\mathrm{R}$, recovery. $P$ values for the outcomes of two-way repeated measures analysis of variance are shown in Table 2. These indicate significant effects of candesartan on $\mathrm{U}_{\mathrm{Na}+} \mathrm{V}$ and $\mathrm{FE}_{\mathrm{Na}+}$ and a significant effect of hypoxia on GFR. However, candesartan did not significantly affect responses to hypoxia.

in GFR ( $-47 \pm 9 \%$; Figure 6). Hemodynamic and excretory responses to plasma volume expansion were not significantly altered by candesartan treatment (Figures $\mathbf{5}$ and $\mathbf{6}$ ).

\section{RESPONSES TO MILD HEMORRHAGE}

After vehicle treatment, mild hemorrhage was accompanied by little change in MAP $(-2 \pm 2 \mathrm{mmHg}$ after removal of $12 \mathrm{ml} / \mathrm{kg}$ blood) but increased $\mathrm{HR}$ ( $40 \pm 6$ beats $/ \mathrm{min})$, reduced CO $(-16 \pm 4 \%)$ and RBF $(-18 \pm 6 \%)$, increased TPR $(18 \pm 4 \%)$ and a tendency for increased RVR $(18 \pm 9 \%, P=0.1)$. After candesartan treatment, MAP fell during hemorrhage $(-14 \pm 1 \mathrm{mmHg})$ and

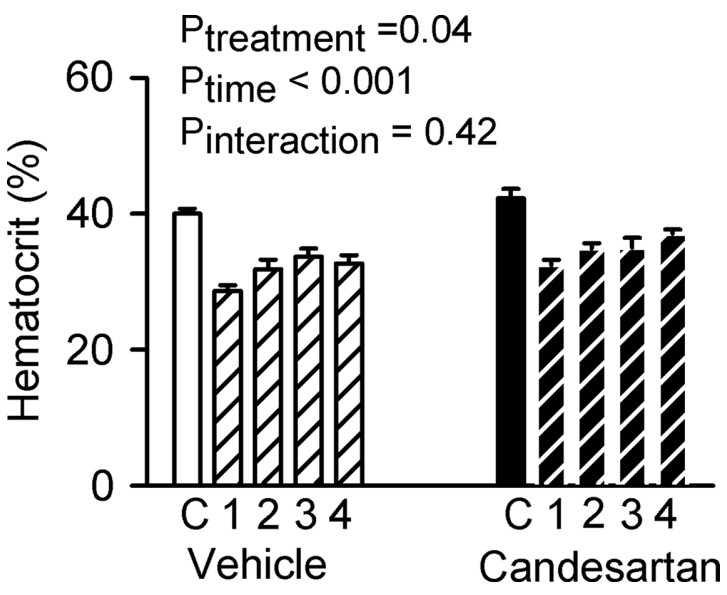

FIGURE 4 | Responses of hematocrit to plasma volume expansion in conscious rabbits treated with candesartan or its vehicle. $\mathrm{C}=$ control, $1,2,3$, and 4 refer to the consecutive 20 min clearance periods after plasma volume expansion. $P$ values are the outcomes of two-way repeated measures analysis of variance. These indicate significant effects of candesartan and plasma volume expansion on hematocrit, but no significant effect of candesartan on the response of hematocrit to plasma volume expansion
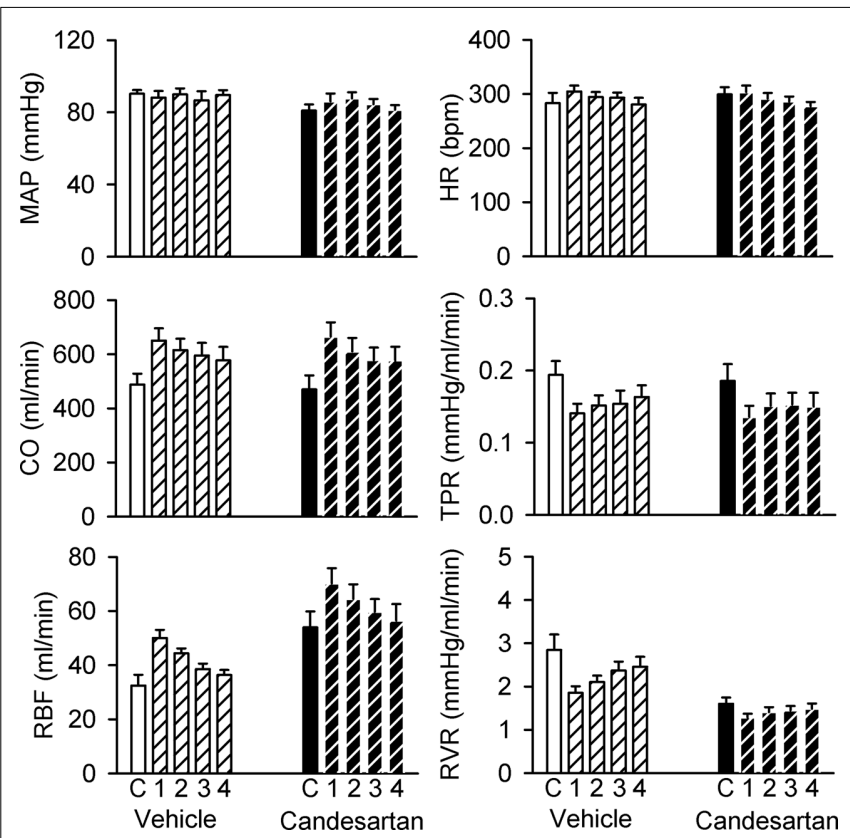

FIGURE 5 | Responses of hemodynamic variables to plasma volume expansion in conscious rabbits treated with candesartan or its vehicle. $M A P$, mean arterial pressure; $H R$, heart rate; $C O$, cardiac output; $R B F$, renal blood flow; TPR, total peripheral resistance; RVR, renal vascular resistance. $C=$ control, $1,2,3$, and 4 refer to the consecutive 20 min clearance periods after plasma volume expansion. $P$ values for the outcomes of two-way repeated measures analysis of variance are shown in Table 2 . These indicate significant effects of candesartan on RBF and RVR and significant changes in CO, RBF, TPR, and RVR in response to plasma volume expansion. However, there were no significant effects of candesartan on the responses of these variables to plasma volume expansion. 

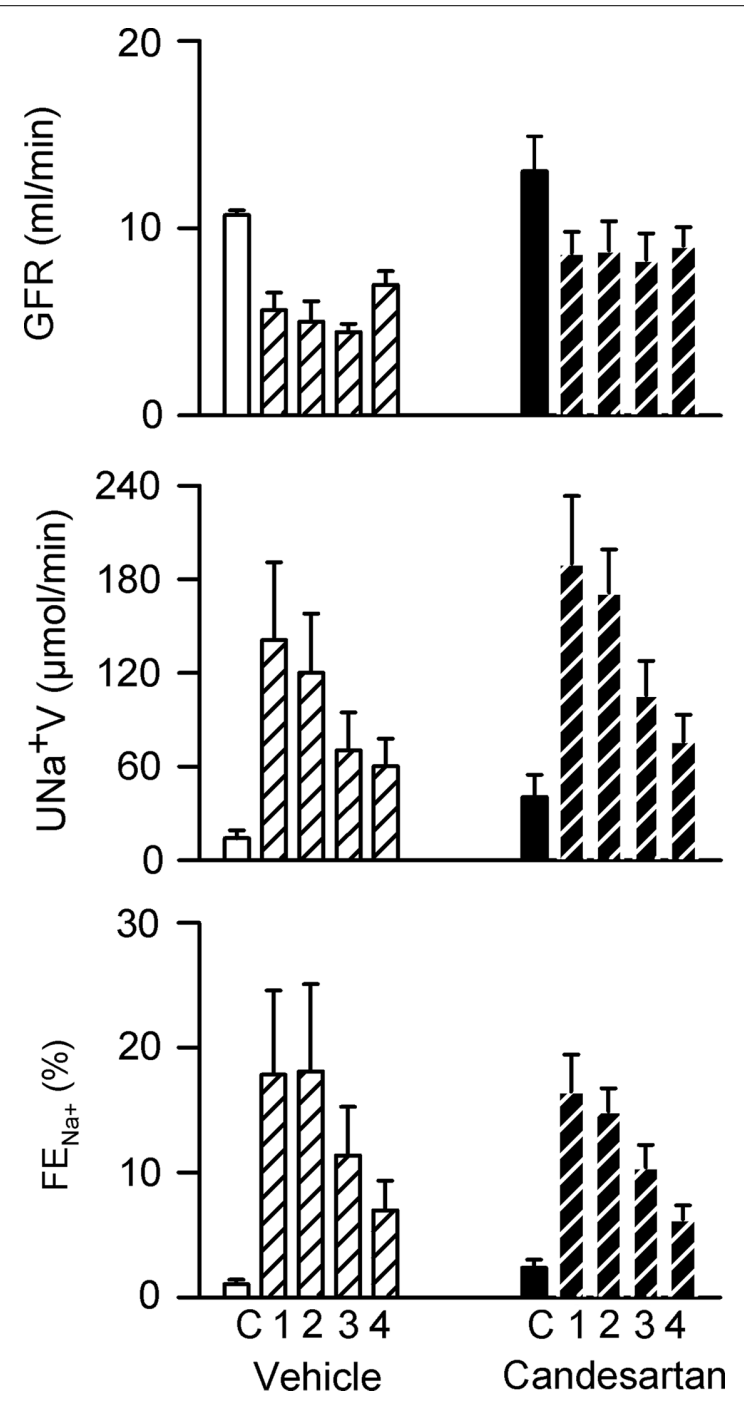

FIGURE 6 | Responses of renal excretory variables to plasma volume expansion in conscious rabbits treated with candesartan or its vehicle. GFR, glomerular filtration rate; $\mathrm{U}_{\mathrm{Na}+} \mathrm{V}$, sodium excretion; $\mathrm{FE}_{\mathrm{Na}+}$, fractional sodium excretion. $\mathrm{C}=$ control, $1,2,3$, and 4 refer to the consecutive $20 \mathrm{~min}$ clearance periods after plasma volume expansion. $P$ values for the outcomes of two-way repeated measures analysis of variance are shown in Table 2. These indicate significant changes in GFR, $U_{\mathrm{Na}+} \mathrm{V}$, and $F E_{\mathrm{Na}+}$ in response to plasma volume expansion. However, there were no significant effects of candesartan on the responses of these variables to plasma volume expansion.

the increases in TPR and RVR seen after vehicle treatment were largely absent (Figure 7).

After vehicle treatment, hemorrhage was not accompanied by significant changes in GFR or sodium excretion. However, the fractional excretion of sodium was consistently reduced, from $1.63 \pm 0.79 \%$ under control conditions to $0.46 \pm 0.11 \%$ after removal of $12 \mathrm{ml} / \mathrm{kg}$ blood. In contrast, GFR ( $-64 \pm 18 \%)$, sodium excretion $(-83 \pm 10 \%)$, and the fractional excretion of sodium (from $1.63 \pm 0.33$ to $0.71 \pm 0.10 \%$ ) fell during hemorrhage after candesartan treatment (Figure 8).
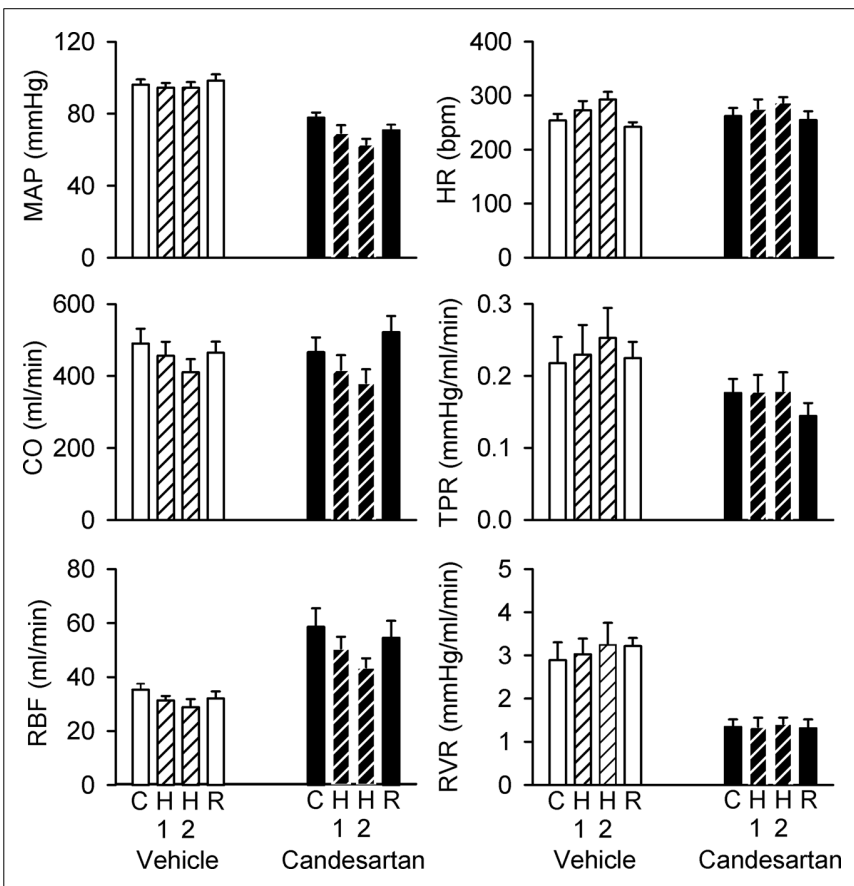

FIGURE 7 | Responses of hemodynamic variables to progressive hemorrhage in conscious rabbits treated with candesartan or its vehicle. $M A P$, mean arterial pressure; $H R$, heart rate; $C O$, cardiac output; RBF, renal blood flow; TPR, total peripheral resistance; RVR, renal vascular resistance. $\mathrm{H} 1=6 \mathrm{ml} / \mathrm{kg}$ blood loss; $\mathrm{H} 2=12 \mathrm{ml} / \mathrm{kg}$ blood loss. $P$ values for the outcomes of repeated measures analysis of variance are shown in Table 2. These indicate significant effects of candesartan on MAP, RBF, and RVR, significant effects of hemorrhage on MAP, HR, CO, and TPR, and significant effects of candesartan on the responses of MAP and CO to hemorrhage.

\section{DISCUSSION}

Our findings support a role for the RAS, through activation of $\mathrm{AT}_{1}$-receptors, in supporting arterial pressure and glomerular filtration in the face of acute blood loss. But the RAS appears to play little role in mediating the renal vasoconstriction, hypofiltration, and antinatriuresis that accompanies hypoxia, or the systemic and renal vasodilatation and natriuresis that accompanies plasma volume expansion. Thus, while the ability of $\mathrm{AT}_{1}$-receptor antagonists to blunt compensatory responses to hypovolemia may contribute toward their antihypertensive efficacy, our findings do not support the notion that these agents acutely blunt the prohypertensive responses to hypoxia or augment the compensatory antihypertensive responses to hypervolemia.

In conscious, normotensive rabbits, candesartan administration acutely reduced MAP. We also observed an increase in RBF (and reduction in RVR) and increased sodium excretion mainly mediated by inhibition of tubular sodium reabsorption. The ability of $\mathrm{AT}_{1}$-receptor antagonists like candesartan to enhance sodium excretion, despite the fact that they reduce MAP, is critical to their longer-term efficacy. That is, they chronically shift the pressure natriuresis relationship to allow excretion of the daily sodium load in the face of chronically lowered arterial pressure. This is one of the desirable actions of an "ideal antihypertensive 

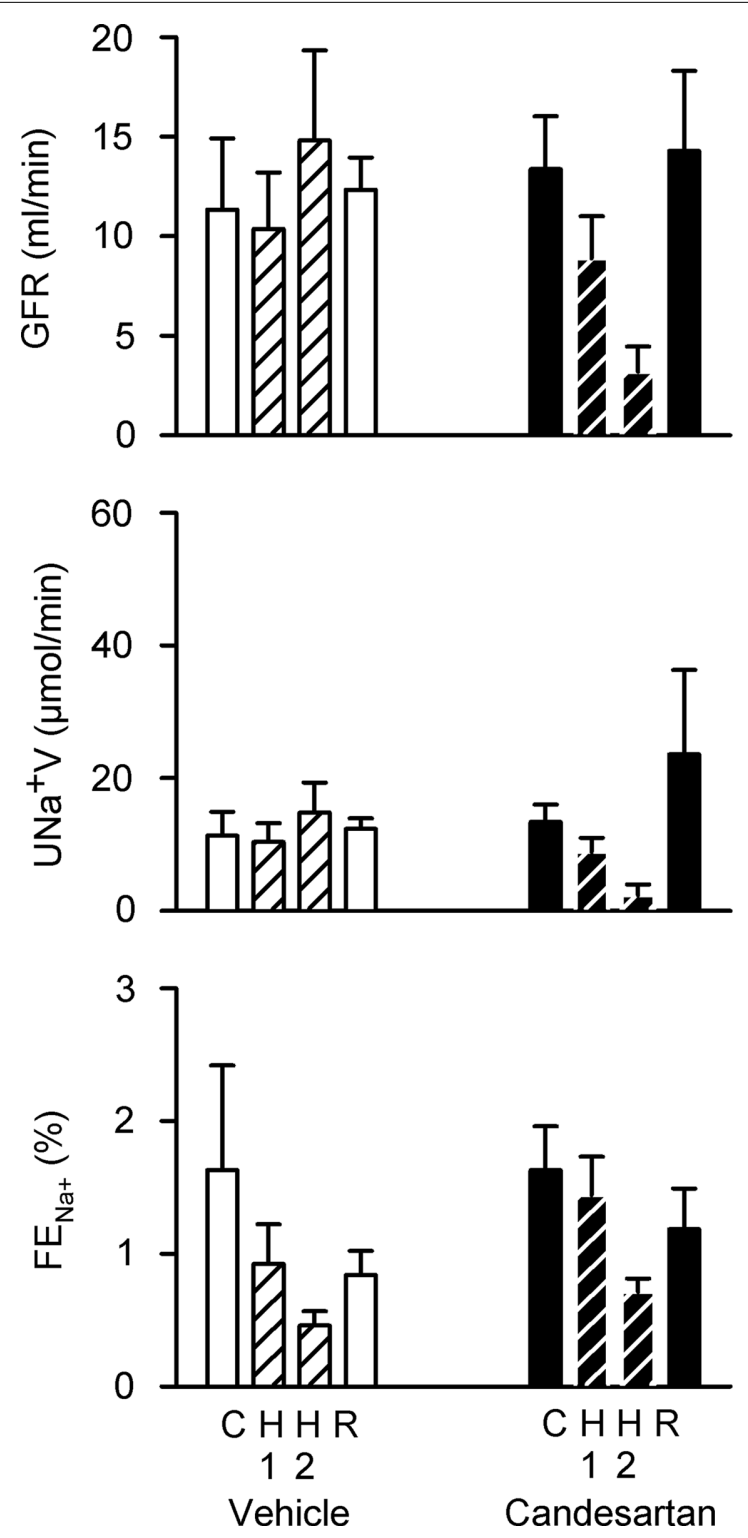

FIGURE 8 | Responses of renal excretory variables to progressive hemorrhage in conscious rabbits treated with candesartan or its vehicle. GFR, glomerular filtration rate; $U_{\mathrm{Na}+} \mathrm{V}$, sodium excretion; $\mathrm{FE}_{\mathrm{Na}+\text {, }}$, fractional sodium excretion. $\mathrm{H} 1=6 \mathrm{ml} / \mathrm{kg}$ blood loss; $\mathrm{H} 2=12 \mathrm{ml} / \mathrm{kg}$ blood loss. $P$ values for the outcomes of two-way repeated measures analysis of variance are shown in Table 2. These failed to detect significant effects of candesartan or hemorrhage on GFR, $\mathrm{U}_{\mathrm{Na}+} \mathrm{V}$, and $\mathrm{FE}_{\mathrm{Na}+}$.

agent" (Evans et al., 2005a,b). Another desirable action would be to modulate cardiovascular reflexes in a way that promotes the lowering of arterial pressure. Such effects could include the blunting of responses to sympatho-excitatory stimuli such as activation of arterial chemoreflexes as occurs in patients with sleep apnea (Prabhakar and Kumar, 2010). Moreover, promotion of natriuresis in response to increased plasma volume and/or enhancement of the depressor response to reductions in blood volume could also be desirable actions of an ideal antihypertensive agent. We assessed the degree to which the $\mathrm{AT}_{1}$-receptor antagonist candesartan fulfills these criteria.

Hypoxia elicits a complex cardiovascular response, mediated partly through activation of arterial chemoreceptors (Prabhakar and Kumar, 2010) and partly through locally mediated changes in vascular tone (Prabhakar and Kumar, 2010). Local hypoxia induces vasodilatation in a range of vascular beds including skeletal muscle (Chalmers et al., 1966). But sympathetic vasomotor drive is increased due to chemoreceptor activation, which mediates vasoconstriction (Chalmers et al., 1965) that is particularly prominent in the kidney (Malpas and Evans, 1998). In conscious rabbits these competing influences often result in little or no change in MAP, CO, or TPR during hypoxia, as in the current study. However, there was a strong tendency for increased RVR. Furthermore, the presence of pre-glomerular vasoconstriction was supported by the finding of reduced GFR during hypoxia. The renal effects of hypoxia are abolished by prior renal denervation (Malpas and Evans, 1998; Leonard et al., 2001), indicating that they are dependent upon activation of renal sympathetic nerve activity. The renal sympathetic nerves mediate renal renin release (Burke et al., 2007), which could contribute to the renal effects of hypoxia. Indeed, hypoxia has been shown to increase plasma renin activity in multiple species (Tuffley et al., 1970; Heyes et al., 1982), including rabbits (Malpas and Evans, 1998; Evans et al., 2007). The resultant increase in circulating angiotensin II could modulate the response to hypoxia at multiple sites, including within the kidney itself (Dibona and Sawin, 2003; Le Fevre et al., 2003; Rajapakse et al., 2005), the carotid body (Leung et al., 2003; Li et al., 2006), and the neural pathways subserving the arterial chemoreflex (Gaudet et al., 1997). Yet we found little impact of $\mathrm{AT}_{1}$-receptor blockade on systemic and renal hemodynamic, and renal excretory responses, to hypoxia. Our findings are consistent with those of previous studies performed in anesthetized animals (Neylon et al., 1996). In the case of severe hypoxia, which often produces hypotension, the RAS appears to play some role in maintenance of renal vascular tone (Liang and Gavras, 1978). Nevertheless, our current findings provide definitive evidence that, in the absence of confounding effects of hypotension as is often observed in rats during hypoxia (Neylon et al., 1996), there is little role of the RAS in the systemic hemodynamic and renal responses to acute hypoxia.

More than 3\% of the adult population experience sleep apnea (Bixler et al., 1998), which results in chronic intermittent hypoxia (Budhiraja et al., 2010). Sleep apnea is a major risk factor for hypertension and cardiovascular disease (Budhiraja et al., 2010). Chronic intermittent activation of the sympathetic nervous system (SNS) in subjects with sleep apnea leads to chronically increased sympathetic vasomotor drive which in turn promotes the development of hypertension (Prabhakar and Kumar, 2010). Activation of the RAS, which has been observed in patients with sleep apnea (Moller et al., 2003), may also contribute to the development of hypertension. Indeed, in experimental animals, chronic blockade of $\mathrm{AT}_{1}$-receptors can blunt the development of hypertension in response to chronic intermittent hypoxia (Fletcher et al., 2002). Furthermore, a recent human study demonstrated that losartan can abolish the sustained increase in arterial pressure observed after a 6-h bout of intermittent hypoxia (Foster et al., 2010). Thus, 
$\mathrm{AT}_{1}$-receptor antagonists appear able to counter many of the prohypertensive consequences of sleep apnea. Adults and children with sleep disordered breathing tend to have increased nocturnal sodium excretion, believed to be mediated chiefly through pressure natriuresis (Warley and Stradling, 1988; Kaditis et al., 2010). Activation of the SNS, and possibly also the RAS, during hypoxia might be expected to limit this pressure natriuresis, and so contribute to the pro-hypertensive effects of sleep apnea. Thus, a desirable property of an antihypertensive pharmacotherapy for patients with sleep apnea would be to blunt the acute sympatho-excitatory effects of hypoxia and/or reduce its influence on renal function. Our current findings suggest that the $\mathrm{AT}_{1}$-receptor antagonist candesartan does not possess these actions.

Another desirable property of an antihypertensive agent would be to promote salt and water excretion in the face of expansion of either extracellular fluid volume or plasma volume. When given acutely, $\mathrm{AT}_{1}$-receptor antagonists enhance the diuretic and natriuretic response to extracellular fluid volume expansion (Andersen et al., 2002). But the natriuretic response to extracellular fluid volume expansion is dominated by the associated reduction in plasma colloid osmotic pressure (Cowley and Skelton, 1991), which is likely to be less evident when plasma volume is expanded by administration of a colloidal solution as in the current study. We are aware of no previous studies that have investigated the impact of $\mathrm{AT}_{1}$-receptor blockade on responses to plasma volume expansion. Plasma volume expansion was accompanied by little change in MAP but increased CO and reduced TPR. RBF and sodium excretion increased yet GFR was reduced. None of these effects were significantly altered by prior candesartan treatment, indicating little role for $\mathrm{AT}_{1}$-receptors in mediating natriuretic responses to plasma volume expansion. These observations and conclusions concord with those from previous studies indicating a pivotal role of cardiac baroreceptor mediated inhibition of renal sympathetic vasomotor drive in the natriuretic response to plasma volume expansion (Morita and Vatner, 1985; Badoer et al., 1998). Thus, the ability of $\mathrm{AT}_{1}$-receptor blockade to enhance natriuretic responses to extracellular fluid volume expansion does not appear to extend to the natriuretic response to plasma volume expansion.

Compensatory responses to hypovolemia act to blunt the blood pressure lowering effects of reductions in extracellular fluid volume and/or blood volume (Evans et al., 2001). We examined the ability of candesartan to blunt these compensatory responses after mild hemorrhage. Candesartan treatment enhanced the depressor response to hemorrhage, both by limiting the increase in TPR and augmenting the fall in CO induced by blood loss. Furthermore, neither GFR nor sodium excretion could be maintained at their control levels after hemorrhage in candesartan-treated rabbits. These observations likely reflect the important role of the RAS in autoregulation of GFR (Hall et al., 1977; Evans et al., 2010). Our observations are largely consistent with those of previous studies. For example, in conscious dogs, Francis et al. (2004) found that losartan treatment exaggerated the reductions in MAP and led to reduced GFR during hemorrhage. At first sight our data may seem to conflict with those of Courneya and Korner (1991), who detected no effect of combined angiotensin converting enzyme inhibition and vasopressin $\mathrm{V}_{1}$-receptor antagonism on the acute circulatory response to hemorrhage in conscious rabbits. However, they did find that this treatment attenuated the recovery of MAP after hemorrhage, a situation analogous to our current experimental protocol in which hemodynamic and renal function were assessed across 20 min periods following blood removal.

Our findings with regard to the effects of candesartan on responses of RVR to hemorrhage deserve some comment. RVR rose during hemorrhage after vehicle treatment, as has been observed previously in conscious rabbits (Courneya and Korner,

Table 2 | Outcomes of two-way repeated measures analysis of variance for data shown in Figures 2, 3, and 5-8.

\begin{tabular}{|c|c|c|c|c|c|c|c|c|c|}
\hline \multirow[t]{2}{*}{ Variable } & \multicolumn{3}{|c|}{ Hypoxia (Figures 1-3) } & \multicolumn{3}{|c|}{ Plasma volume expansion (Figures 4-6) } & \multicolumn{3}{|c|}{ Hemorrhage (Figures 7 and 8 ) } \\
\hline & Treatment & Time & Interaction & Treatment & Time & Interaction & Treatment & Time & Interaction \\
\hline MAP & 0.003 & 0.23 & 0.51 & 0.36 & 0.32 & 0.28 & 0.001 & 0.001 & 0.001 \\
\hline $\mathrm{HR}$ & 0.17 & 0.001 & 0.09 & 0.94 & 0.28 & 0.39 & 0.57 & $<0.001$ & 0.55 \\
\hline $\mathrm{CO}$ & 0.40 & 0.12 & 0.22 & 0.83 & $<0.001$ & 0.36 & 0.77 & $<0.001$ & 0.01 \\
\hline $\mathrm{RBF}$ & 0.003 & 0.14 & 0.57 & 0.03 & 0.004 & 0.85 & 0.04 & 0.06 & 0.20 \\
\hline TPR & 0.05 & 0.06 & 0.14 & 0.68 & $<0.001$ & 0.45 & 0.10 & 0.05 & 0.12 \\
\hline RVR & 0.02 & 0.09 & 0.38 & 0.01 & 0.03 & 0.16 & 0.03 & 0.25 & 0.33 \\
\hline GFR & 0.06 & 0.03 & 0.62 & 0.15 & 0.04 & 0.29 & 0.34 & 0.36 & 0.16 \\
\hline$U_{\mathrm{Na}+} \mathrm{V}$ & 0.01 & 0.09 & 0.09 & 0.09 & 0.02 & 0.23 & 0.73 & 0.09 & 0.64 \\
\hline $\mathrm{FE}_{\mathrm{Na}+}$ & 0.005 & 0.32 & 0.12 & 0.86 & 0.01 & 0.73 & 0.43 & 0.07 & 0.69 \\
\hline
\end{tabular}

$P$ values were conservatively adjusted, to account for compound asymmetry, using the Greenhouse-Geisser correction (Ludbrook, 1994). MAP, mean arterial pressure; HR, heart rate; CO, cardiac output; RBF, renal blood flow; TPR, total peripheral resistance; RVR, renal vascular resistance; GFR, glomerular filtration rate; $U_{\text {Na+ }}$, sodium excretion; $F E_{\mathrm{Na}+}$, the fractional excretion of sodium. Degrees of freedom (df) for "treatment" are 1 and 6 for all variables except RBF and RVR (1 and 3). For hypoxia, degrees of freedom for "time" and the "treatment(time interaction" are 2 and 12 except for RBF and RVR (2 and 6). For hemorrhage, degrees of freedom for time and the treatment(time interaction are 3 and 18 except for RBF and RVR (3 and 9). For plasma volume expansion, degrees of freedom for time and the treatment(time interaction are 4 and 24 except for $R B F$ and $R V R$ (4 and 16). $P$ values $\leq 0.05$ are in bold font. 
1991; Malpas et al., 1998). This response has been attributed predominantly to the influence of increased renal sympathetic nerve activity, since it was abolished by total autonomic blockade or sinoaortic baroreceptor denervation (Courneya and Korner, 1991) and blunted by prior renal denervation (Malpas et al., 1998). Furthermore, it was little affected by combined blockade of the RAS (angiotensin converting enzyme inhibition) and vasopressin $\mathrm{V}_{1}$-receptors (Courneya and Korner, 1991). Yet in our current study RVR did not increase significantly during hemorrhage after candesartan treatment, raising the possibility of some role for angiotensin II in the renal vasoconstrictor response to hemorrhage. However, we were unable to detect a significant interaction between treatment and time in our factorial analysis of these data (Table 2), so this aspect of our experiment must be interpreted with care. Nevertheless, our current data support the notion that the ability of $\mathrm{AT}_{1}$-receptor antagonists to blunt compensatory responses to hypovolemia may contribute to the efficacy of this therapeutic modality for hypertension. It could also be argued that such an effect could be deleterious for patients on $\mathrm{AT}_{1}$-receptor antagonist therapy who are subjected to unexpected blood loss.

A major strength of our experimental approach in the current study was the use of a within-animal design. But important limitations must be acknowledged. Firstly, because we administered candesartan systemically, we could not determine the relative contributions of peripheral and central $\mathrm{AT}_{1}$-receptors to the effects we observed. Candesartan can cross the blood brain barrier (Nishimura et al., 2000), so both peripheral and central actions could contribute to its effects on the response to hemorrhage. However, it seems likely that peripheral effects dominate, since the peptide angiotensin receptor antagonist saralasin, which is unlikely to cross the blood brain barrier, augmented the depressor response to hemorrhage when given intravenously (Spielman et al., 1975).

\section{REFERENCES}

Andersen, J. L., Sandgaard, N. C., and Bie, P. (2002). Volume expansion during acute angiotensin II receptor (AT(1)) blockade and NOS inhibition in conscious dogs. Am. J. Physiol. Regul. Integr. Comp. Physiol. 282, R1140-R1148.

Badoer, E., Moguilevski, V., and McGrath, B. P. (1998). Cardiac afferents play the dominant role in renal nerve inhibition elicited by volume expansion in the rabbit. Am. J. Physiol. 274, R383-R388.

Bixler, E. O., Vgontzas, A. N., Ten Have, T., Tyson, K., and Kales, A. (1998). Effects of age on sleep apnea in men: I. Prevalence and severity. Am. J. Respir. Crit. Care Med. 157, 144-148.

Blake, D. W., Evans, R. G., Ludbrook, J., and Petring, O. U. (1994). Interactions between the circulatory effects of central hypovolaemia and arterial hypoxia in conscious rabbits. Clin. Exp. Pharmacol. Physiol. 21, 383-396.

Nevertheless, the effects of $\mathrm{AT}_{1}$-receptor blockade may be partly mediated within the central nervous system, since Lee et al. (1995) demonstrated that intracerebroventricular administration of low doses of losartan or saralasin can blunt compensatory responses to hemorrhage, while Mathai et al. (1997) found that intracerebroventricular losartan reduced the level of blood loss required to elicit the decompensatory phase of the response to hemorrhage (Evans et al., 2001). A second limitation of our study was that we did not obtain any measures of the activity of the SNS, so interpretation of our findings with respect to autonomic control of the circulation must be associated with caution. A third limitation of our current study relates to the variability of our measures of renal excretory function. As a consequence, the power of our experiment to detect effects on renal excretory function was not as great as the power to detect changes in systemic and renal hemodynamics. This may account for our inability to detect some expected effects, such as reduced sodium excretion during hypoxia and after hemorrhage. Finally, because we studied the acute effects of candesartan in normotensive animals, our findings may not be generalizable to the effects of chronic treatment with $\mathrm{AT}_{1}$-receptor antagonists in hypertension.

In conclusion, our findings support a role of the RAS, through activation of $\mathrm{AT}_{1}$-receptors, in supporting MAP and GFR during hypovolemia. In contrast, $\mathrm{AT}_{1}$-receptors appear to play little role in mediating the renal vasoconstriction, hypofiltration, and antinatriuresis accompanying hypoxia, or the systemic and renal vasodilatation and natriuresis accompanying plasma volume expansion.

\section{ACKNOWLEDGMENTS}

This work was supported by grants from the National Health and Medical Research Council of Australia $(367631,384101)$ and the National Heart Foundation of Australia (G08M3810).

haemorrhage in rabbits. J. Physiol. 437, 393-407.

Cowley, A. W. Jr., and Skelton, M. M. (1991). Dominance of colloid osmotic pressure in renal excretion after isotonic volume expansion. Am. J. Physiol. 261, H1214-H1225.

Dibona, G. F., and Sawin, L. L. (2003) Losartan corrects abnormal frequency response of renal vasculature in congestive heart failure. Am. J. Physiol. Heart Circ. Physiol. 285, H1857-H1863.

Evans, R. G., Burke, S. L., Lambert, G. W., and Head, G. A. (2007). Renal responses to acute reflex activation of renal sympathetic nerve activity and renal denervation in secondary hypertension. Am. J. Physiol. Regul. Integr. Comp. Physiol. 293, R1247-R1256.

Evans, R. G., Eppel, G. A., Michaels, S., Burke, S. L., Nematbakhsh, M., Head, G. A., Carroll, J. F., and O'Connor, P. M. (2010). Multiple mechanisms act to maintain kidney oxygenation during renal ischemia in anesthetized rabbits. Am. J. Physiol. Renal Physiol. 298, F1235-F1243.

Evans, R. G., Kett, M. M., Shweta, A., Fitzgerald, S. M., Denton, K. M., Eppel, G. A., Edgley, A. J., and Anderson, W. P. (2005a). New physiological targets within the kidney for antihypertensive therapy. Drug Des. Rev. Online 2, 167-178.

Evans, R. G., Majid, D. S., and Eppel, G. A. (2005b). Mechanisms mediating pressure natriuresis: what we know and what we need to find out. Clin. Exp. Pharmacol. Physiol. 32, 400-409.

Evans, R. G., Ventura, S., Dampney, R. A., and Ludbrook, J. (2001). Neural mechanisms in the cardiovascular responses to acute central hypovolaemia. Clin. Exp. Pharmacol. Physiol. 28, 479-487.

Fletcher, E. C., Orolinova, N., and Bader, M. (2002). Blood pressure response to chronic episodic hypoxia: the 
renin-angiotensin system. J. Appl. Physiol. 92, 627-633.

Foster, G. E., Hanly, P. J., Ahmed, S. B., Beaudin, A. E., Pialoux, V., and Poulin, M. J. (2010). Intermittent hypoxia increases arterial blood pressure in humans through a renin-angiotensin systemdependent mechanism. Hypertension $56,369-377$.

Francis, R. C., Hohne, C., Kaczmarczyk, G., and Boemke, W. (2004). Effect of angiotensin II and endothelin-1 receptor blockade on the haemodynamic and hormonal changes after acute blood loss and after retransfusion in conscious dogs. Acta Physiol. Scand. 180, 319-328.

Fridman, K. U., Wysocki, M., Friberg, P. R., and Andersson, O. K. (1999). Candesartan cilexetil in hypertension: effects of six weeks' treatment on haemodynamics, baroreceptor sensitivity and the renin-angiotensin-aldosterone system. Blood Press. 8, 242-247.

Gaudet, E. A., Godwin, S. J., Lukoshkova, E., and Head, G. A. (1997). Effect of central endogenous angiotensin II on sympathetic activation induced by hypoxia. Clin. Exp. Hypertens. 19, 913-923.

Guild, S. J., Eppel, G. A., Malpas, S. C., Rajapakse, N. W., Stewart, A., and Evans, R. G. (2002). Regional responsiveness of renal perfusion to activation of the renal nerves. Am. J. Physiol. Regul. Integr. Comp. Physiol. 283, R1177-R1186.

Hajjar, I. (2005). Postural blood pressure changes and orthostatic hypotension in the elderly patient: impact of antihypertensive medications. Drugs Aging 22, 55-68.

Hall, J. E., Guyton, A. C., and Cowley, A. W. Jr. (1977). Dissociation of renal blood flow and filtration rate autoregulation by renin depletion. Am. J. Physiol. 232, F215-F221.

Heyes, M. P., Farber, M. O., Manfredi, F., Robertshae, D., Weinberger, M., Finiberg, M., and Robertson, G. (1982). Acute effects of hypoxia on renal endocrine function in normal humans. Am. J. Physiol. 243, R265-R270.

Kaditis, A. G., Alexopoulos, E. I., Evangelopoulos, K., Kostadima, E., Varlami, V., Boultadakis, E., Liakos, N., Zakynthinos, E., Zintzaras, E., and Gourgoulianis, K. (2010). Correlation of urinary excretion of sodium with severity of sleep-disordered breathing in children: a preliminary study. Pediatr. Pulmonol. 45, 999-1004.

Le Fevre, M. E., Guild, S. J., Ramchandra, R., Barrett, C. J., and Malpas, S.
C. (2003). Role of angiotensin II in the neural control of renal function. Hypertension 41, 583-591.

Lee, W. J., Yang, E. K., Ahn, D. K., Park, Y. Y., Park, J. S., and Kim, H. J. (1995). Central ANG II-receptor antagonists impair cardiovascular and vasopressin response to hemorrhage in rats. Am. J. Physiol. 268, R1500-R1506.

Leonard, B. L., Malpas, S. C., Denton, K. M., Madden, A. C., and Evans, R. G. (2001). Differential control of intrarenal blood flow during reflex increases in sympathetic nerve activity. Am. J. Physiol. Regul. Integr. Comp. Physiol. 280, R62-R68.

Leung, P. S., Fung, M. L., and Tam, M. S. C. (2003). Renin-angiotensin system in the carotid body. Int. J. Biochem. Cell Biol. 35, 847-854.

Li, Y. L., Xia, X. H., Zheng, H., Gao, L., Li, Y. F., Liu, D., Patel, K. P., Wang, W., and Schultz, H. D. (2006). Angiotensin II enhances carotid body chemoreflex control of sympathetic outflow in chronic heart failure rabbits. Cardiovasc. Res. $71,129-138$.

Liang, C. S., and Gavras, H. (1978). Renin-angiotensin system inhibition in conscious dogs during acute hypoxemia. Effects on systemic hemodynamics, regional blood flows, and tissue metabolism. J. Clin. Invest. 62, 961-970.

Ludbrook, J. (1994). Repeated measurements and multiple comparisons in cardiovascular research. Cardiovasc. Res. 28, 303-311.

Ludbrook, J., and Graham, W. F. (1984). The role of cardiac receptor and arterial baroreceptor reflexes in control of the circulation during acute change of blood volume in the conscious rabbit. Circ. Res. 54, 424-435.

Malpas, S. C., and Evans, R. G. (1998). Do different levels and patterns of sympathetic activation all provoke renal vasoconstriction? J. Auton. Nerv. Syst. 69, 72-82.

Malpas, S. C., Evans, R. G., Head, G. A., and Lukoshkova, E. V. (1998). Contribution of renal nerves to renal blood flow variability during hemorrhage. Am. J. Physiol. 274, R1283-R1294.

Mathai, M. L., Pennington, G. L., and McKinley, M. J. (1997). The effect of angiotensin AT1 receptor blockade in the brain on the maintenance of blood pressure during haemorrhage in sheep. Acta Physiol. Scand. 161, 495-502.

Moller, D. S., Lind, P., Strunge, N., and Pedersen, E. B. (2003).
Abnormal vasoactive hormones and 24-hour blood pressure in obstructive sleep apnea. Am. J. Hypertens. 16 274-280.

Morita, H., and Vatner, S. F. (1985). Effects of volume expansion on renal nerve activity, renal blood flow, and sodium and water excretion in conscious dogs. Am. J. Physiol. 249, F680-F687.

Muntner, P., Krousel-Wood, M., Hyre, A. D., Stanley, E., Cushman, W. C., Cutler, J. A., Piller, L. B., Goforth, G. A., and Whelton, P. K. (2009). Antihypertensive prescriptions for newly treated patients before and after the main antihypertensive and lipidlowering treatment to prevent heart attack trial results and seventh report of the joint national committee on prevention, detection, evaluation, and treatment of high blood pressure guidelines. Hypertension 53 617-623.

Neylon, M., Marshall, J. M., and Johns, E. J. (1996). The role of the reninangiotensin system in the renal response to moderate hypoxia in the rat. J. Physiol. 491.2, 479-488.

Nishimura, Y., Ito, T., Hoe, K., and Saavedra, J. M. (2000). Chronic peripheral administration of the angiotensin II AT(1) receptor antagonist candesartan blocks brain AT(1) receptors. Brain Res. 871 29-38.

Norman, M. U., Lew, R. A., Smith, A. I., Denton, K. M., and Evans, R. G. (2001). Metalloendopeptidases EC 3.4.24.15 and EC 3.4.24.16 and bradykinin B2 receptors do not play important roles in renal wrap hypertension in rabbits. Clin. Exp. Pharmacol. Physiol. 28, 836-841.

Ponchon, P., and Elghozi, J. L. (1997). Contribution of humoral systems to the recovery of blood pressure following severe haemorrhage. $J$. Auton. Pharmacol. 17, 319-329.

Prabhakar, N. R., and Kumar, G. K. (2010). Mechanisms of sympathetic activation and blood pressure elevation by intermittent hypoxia. Respir. Physiol. Neurobiol. 174, 156-161.

Rajapakse, N. W., Sampson, A. K., Eppel, G. A., and Evans, R. G. (2005). Angiotensin II and nitric oxide in neural control of intrarenal blood flow. Am. J. Physiol. Regul. Integr. Comp. Physiol. 289, R745-R754

Riccioni, G., Vitulano, N., Zanasi, A., Bellocci, F., and D'Orazio, N. (2010). Aliskiren: beyond blood pressure reduction. Expert Opin. Investig. Drugs 19, 1265-1274.
Sharma, A. M. (2004). Is there a rationale for angiotensin blockade in the management of obesity hypertension? Hypertension 44, 12-19.

Shweta, A., Malpas, S. C., Anderson, W. P., and Evans, R. G. (1999). Effects of naloxone on the haemodynamic and renal functional responses to plasma volume expansion in conscious rabbits. Pflugers Arch. 439, 150-157.

Spielman, W. S., Zatzman, M. L., Freeman, R. H., Davis, O. J., and Johnson, J. A. (1975). Arterial pressure regulation during hemorrhage: homeostatic role of angiotensin II. Proc. Soc. Exp. Biol. Med. 149, 19-22.

Tomoda, F., Lew, R. A., Smith, A. I., Madden, A. C., and Evans, R. G. (1996). Role of bradykinin receptors in the renal effects of inhibition of angiotensin converting enzyme and endopeptidases 24.11 and 24.15 in conscious rabbits. Br. J. Pharmacol. 119, 365-373.

Tuffley, R. E., Rubenstein, D., Slater, J. D. H., and William, E. S. (1970). Serum renin activity during exposure to hypoxia. J. Endocrinol. 48, 497-510.

Vitry, A., and Lai, Y. H. (2009). Advertising of antihypertensive medicines and prescription sales in Australia. Intern. Med. J. 39, 728-732.

Warley, A. R., and Stradling, J. R. (1988). Abnormal diurnal variation in salt and water excretion in patients with obstructive sleep apnoea. Clin. Sci. 74, 183-185.

Conflict of Interest Statement: The authors declare that the research was conducted in the absence of any commercial or financial relationships that could be construed as a potential conflict of interest.

Received: 03 June 2011; paper pending published: 20 June 2011; accepted: 10 July 2011; published online: 19 July 2011.

Citation: Xu TB, Eppel GA, Head GA and Evans RG (2011) Angiotensin II type 1 receptors and systemic hemodynamic and renal responses to stress and altered blood volume in conscious rabbits. Front. Physio. 2:40. doi 10.3389/fphys.2011.00040

This article was submitted to Frontiers in Integrative Physiology, a specialty of Frontiers in Physiology.

Copyright ๑ $2011 \mathrm{Xu}$, Eppel, Head and Evans. This is an open-access article subject to a non-exclusive license between the authors and Frontiers Media SA, which permits use, distribution and reproduction in other forums, provided the original authors and source are credited and other Frontiers conditions are complied with. 